\title{
An Electrochemical Quartz Crystal Microbalance Study into the Deposition of Manganese Dioxide
}

\author{
by \\ Michael P. Owen, Geoffrey A. Lawrance and Scott W. Donne* \\ Discipline of Chemistry \\ University of Newcastle \\ Callaghan, NSW 2308 \\ Australia
}

\begin{abstract}
\end{abstract}
An electrochemical quartz crystal microbalance (EQCM) has been used to study the effects of electrolyte composition ( $\mathrm{MnSO}_{4}$ and $\mathrm{H}_{2} \mathrm{SO}_{4}$ concentrations) and anodic current density on the electrodeposition of manganese dioxide. The EQCM, in tandem with the electrode voltage during deposition, has been used to characterize features of the deposition mechanism such as the relative lifetime of the $\mathrm{Mn}(\mathrm{III})$ intermediate, the rate of soluble $\mathrm{Mn}(\mathrm{III})$ hydrolysis to form $\mathrm{MnOOH}$, and the porosity of the resultant manganese dioxide deposit as a function of crystal nucleation. The connection between the results obtained here and commercial electrodeposition of manganese dioxide were also discussed.

*Corresponding author 


\section{INTRODUCTION}

\subsection{Manganese Dioxide as a Battery Material}

In the modern electronic world consumers have access to a wide range of portable devices. This degree of portability has arisen as a result of parallel developments in both the electronics and battery industries. The demands on scientists and engineers in the latter has been significant since there is a competitive need to keep pace with developments made in the field of microelectronics. In general the demand has been to implement batteries that can cope with the increasing power requirements of modern electronic devices.

Many battery systems are available to consumers to power their electronic devices. However, for many years now cells employing manganese dioxide based cathodes have been most popular. Falling within this category is the ubiquitous aqueous alkaline $\mathrm{Zn}-\mathrm{MnO}_{2}$ cell, the manganese dioxide contained within being the subject of this work. The popularity of the alkaline manganese dioxide cathode arises from a unique combination of its physico-chemical, electrochemical, environmental and economic properties. Despite its popularity, there are still many fundamental uncertainties concerning its production and properties that need to be resolved.

The preferred manganese dioxide phase in alkaline electrolytes is $\gamma-\mathrm{MnO}_{2}$. In simple terms this structure is best described as a microscopic intergrowth between the pyrolusite $\left(\beta-\mathrm{MnO}_{2}\right)$ and ramsdellite forms of manganese dioxide, as shown in Figure 1 [1]. Here the basic building block for the structure is the [MnO6] octahedra (manganese at the centre and oxygen at each of the vertices), which in various edge and corner sharing arrangements leads to different structural varieties of manganese dioxide. Added structural complexity arises as a result of the presence of features such as cation vacancies, lower valent manganese species and structural water; i.e.,

$$
\left(\mathrm{Mn}^{4+}\right)_{1-\mathrm{x}-\mathrm{y}} \cdot(\square)_{\mathrm{x}} \cdot\left(\mathrm{Mn}^{3+}\right)_{\mathrm{y}} \cdot\left(\mathrm{O}^{2-}\right)_{2-4 \mathrm{x}-\mathrm{y}} \cdot\left(\mathrm{OH}^{-}\right)_{4 \mathrm{x}+\mathrm{y}}
$$

where $\square$ represents a cation vacancy, and $\mathrm{x}$ and $\mathrm{y}$ are the mole fractions of cation vacancies and lower valent $\mathrm{Mn}^{3+}$ ions, respectively [2, 3]. Note that the structural water is present as protons 
associated with oxide ions to compensate for any charge discrepancies. There is also literature indicating the presence of microtwinning in the $\gamma-\mathrm{MnO}_{2}$ structure [4]; however, the debate as to its presence is still ongoing $[5,6]$. With this brief description in mind, it is clear that there is considerable breadth in classifying a structure as $\gamma-\mathrm{MnO}_{2}$. However, experience would dictate that the range of structural compositions with superior electrochemical performance is very narrow indeed. Of the numerous methods available to prepare $\gamma-\mathrm{MnO}_{2}$, electrodeposition is preferred because of the ease of production at scale.

\subsection{Electrodeposition of Manganese Dioxide}

Electrolytic production of $\gamma-\mathrm{MnO}_{2}$ occurs through the electrolysis of a hot acidic $\left(\mathrm{H}_{2} \mathrm{SO}_{4}\right)$ solution of $\mathrm{MnSO}_{4}$, using titanium as the anode substrate and either carbon or copper as the cathode substrate; i.e.,

Anode (Ti): $\quad \mathrm{Mn}^{2+}+2 \mathrm{H}_{2} \mathrm{O} \rightarrow \mathrm{MnO}_{2}+4 \mathrm{H}^{+}+2 \mathrm{e}^{-}$

Cathode $(\mathrm{C} / \mathrm{Cu})$ :

$$
2 \mathrm{H}^{+}+2 \mathrm{e}^{-} \rightarrow \mathrm{H}_{2}
$$

Overall:

$$
\mathrm{Mn}^{2+}+2 \mathrm{H}_{2} \mathrm{O} \rightarrow \mathrm{MnO}_{2}+\mathrm{H}_{2}+2 \mathrm{H}^{+}
$$

Inherent with this production method are the variables of anodic current density, electrolyte composition $\left(\left[\mathrm{Mn}^{2+}\right]\right.$ and $\left.\left[\mathrm{H}_{2} \mathrm{SO}_{4}\right]\right)$, and temperature. After sufficient deposition, the $\gamma-\mathrm{MnO}_{2}$ is mechanically removed from the anode before being ground, washed, neutralized and dried. This method of production leads to the material classification of EMD (electrolytic manganese dioxide) [7].

As mentioned above, the synthesis conditions for the preferred EMD are anticipated to be rather narrow. Therefore, it is important to obtain an appreciation for the electrodeposition mechanism so as to be able to understand what effect the synthesis conditions have on EMD properties and performance. Most studies to date on EMD deposition have been empirical in nature, focussed on identifying the conditions for optimum production quantities and quality. The few fundamental studies that have been completed (e.g., Fleischmann et al. [8], Cartwright and Paul [9- 
11], Preisler [12], and Kao and Weibull [13]) indicate the importance of $\mathrm{Mn}^{2+}$ oxidation, intermediate species precipitation, and then dehydration as important steps. Recent electrochemical studies (RDE and RRDE voltammetry) in our own laboratory [14] have indicated that the acid concentration is pivotal in determining the actual deposition mechanism. More specifically, in low acid concentration electrolytes $\left(<1.0 \mathrm{M} \mathrm{H}_{2} \mathrm{SO}_{4}\right)$ the preferred $\mathrm{Mn}^{2+}$ oxidation product is $\mathrm{MnOOH}$, which then undergoes solid state oxidation to $\mathrm{MnO}_{2}$. However, in more concentrated acid electrolytes the longevity of the soluble $\mathrm{Mn}^{3+}$ intermediate (i.e., $\left.\left[\mathrm{Mn}\left(\mathrm{H}_{2} \mathrm{O}\right)_{6}\right]^{3+}\right)$ is increased, placing a greater dependence on its disproportionation to form a solid $\mathrm{MnO}_{2}$ product.

To further understand the electrodeposition mechanism we have therefore conducted an electrochemical quartz crystal microbalance (EQCM) study into the effects of electrolyte composition and anodic current density on the electrodeposition mechanism.

\section{EXPERIMENTAL}

\subsection{Electrolyte Solutions}

All electrolytes used in this work were prepared from AR grade reagents and Milli-Q ultrapure water. The electrolytes used for manganese dioxide deposition were prepared from $\mathrm{MnSO}_{4} \cdot \mathrm{H}_{2} \mathrm{O}$ and concentrated $\mathrm{H}_{2} \mathrm{SO}_{4}$, while calibration of the EQCM was done with $\mathrm{CuSO}_{4} \cdot 5 \mathrm{H}_{2} \mathrm{O}$.

\subsection{Electrochemical Protocol}

EQCM measurements were conducted with a Stanford Research Systems QCM200 Quartz Crystal Microbalance Controller, coupled with a QCM25 Crystal Oscillator loaded with a Au-

coated $5 \mathrm{MHz}$ quartz crystal. The area of the $\mathrm{Au}$ electrode was $1.33 \mathrm{~cm}^{2}$. Control of the electrochemical aspects of the experiment was accomplished with a Perkin Elmer VMP multichannel potentiostat/galvanostat. Two channels from the VMP were employed; one to apply the 
bias current/potential to the Au on the quartz surface, and the other to monitor the output from the microbalance with $\Delta \mathrm{f}=\mathrm{a}_{0} \mathrm{~V}$, the conversion factor $\mathrm{a}_{0}$ being dependent on the change in frequency $(\Delta \mathrm{f})$ range used by the controller.

The first step in each experiment was calibration of the quartz crystal. This was achieved by immersing the QCM25 Crystal Oscillator into a well stirred acidic $10 \mathrm{mM} \mathrm{Cu}{ }^{2+}\left(1 \mathrm{M} \mathrm{H}_{2} \mathrm{SO}_{4}\right)$ solution and galvanostatically depositing copper at $0.1 \mathrm{~mA}\left(0.075 \mathrm{~mA} / \mathrm{cm}^{2}\right)$ for 30 seconds. A Pt counter electrode and saturated calomel reference electrode (SCE) were also used to complete the electrochemical cell. Immediately following this the copper was anodically stripped from the $\mathrm{Au}$ surface back into solution using the same magnitude current for 35 seconds to ensure complete removal. After the deposition half cycle the frequency change for the quartz crystal $(\Delta \mathrm{f})$ was combined with the predicted electrode mass change for $\mathrm{Cu}^{2+}+2 \mathrm{e}^{-} \rightarrow \mathrm{Cu}(\Delta \mathrm{m})$ using the Sauerbrey equation [15]

$$
\Delta \mathrm{f}=-\mathrm{C}_{\mathrm{f}} \cdot \Delta \mathrm{m}
$$

to determine the sensitivity factor $\mathrm{C}_{\mathrm{f}}$ for the quartz crystal. While similar, each Au-coated quartz crystal had a unique fundamental frequency, and so for each manganese dioxide electrodeposition experiment the crystal was calibrated immediately beforehand using this procedure. In general though, $\mathrm{C}_{\mathrm{f}}$ for each crystal was comparable to the theoretical sensitivity factor of $56.6 \mathrm{~Hz} / \mu \mathrm{g}$.

After calibration the Crystal Oscillator was removed from the $\mathrm{Cu}^{2+}$ solution and rinsed thoroughly with Milli-Q water. The electrolyte in the electrochemical cell was then changed to be a suitable acidified $\mathrm{MnSO}_{4}$ solution and the Crystal Oscillator re-immersed into the cell. When the fundamental frequency of the crystal had equilibrated in the new electrolyte, the anodic electrodeposition of manganese dioxide onto the Au-coated quartz crystal was carried out under a variety of conditions. All experiments were conducted at $22 \pm 1^{\circ} \mathrm{C}$.

\section{RESULTS AND DISCUSSION}




\subsection{Acid Concentration Effects}

Figure 2 contains a typical example of the effects of acid concentration on the deposition of manganese dioxide as recorded using the EQCM. In this example a $1.0 \mathrm{M}$ solution of $\mathrm{MnSO}_{4}$, with $\mathrm{H}_{2} \mathrm{SO}_{4}$ concentrations ranging from 0-1 M, was anodically electrolyzed using $0.1 \mathrm{~mA}(0.075$ $\mathrm{mA} \cdot \mathrm{cm}^{-2}$ ) for 15 seconds, after which the deposited material was cathodically stripped using the same magnitude current density, applied again for 15 seconds (Figure 2(a)). Recorded during the experiment were the Au disk voltage (Figure 2(b)) and the mass change during both deposition and stripping (Figure 2(c)).

What is immediately apparent from the mass change data in Figure 2(c) is that as the $\mathrm{H}_{2} \mathrm{SO}_{4}$ concentration is increased the amount of deposited material decreases considerably. Furthermore, except for the highest $\mathrm{H}_{2} \mathrm{SO}_{4}$ concentration $(1.0 \mathrm{M})$, the amount of material deposited was always greater than that predicted from the stoichiometry of Eqn (2) and the amount of charge passed. To begin to explain this behaviour we need to first identify potential causes for a heavier than expected deposit. Manganese dioxide is typically a porous material, so the inclusion of electrolyte into pores can account for additional mass, as can the presence of structural water. To elaborate further on the latter point we need to understand manganese speciation in the acidic electrolytes used here. Firstly, $\mathrm{Mn}(\mathrm{II})$ is stable over the entire $\mathrm{H}_{2} \mathrm{SO}_{4}$ concentration range used $\left(\mathrm{pK}_{\mathrm{a}}=10.59\right.$ [16]), existing as the hexa-aquo octahedral complex $\left[\mathrm{Mn}\left(\mathrm{H}_{2} \mathrm{O}\right)_{6}\right]^{2+}$. Unlike $\mathrm{Mn}(\mathrm{II})$, the stability of the analogous $\mathrm{Mn}(\mathrm{III})$ species $\left[\mathrm{Mn}\left(\mathrm{H}_{2} \mathrm{O}\right)_{6}\right]^{3+}$ is very much dependent on the $\mathrm{H}_{2} \mathrm{SO}_{4}$ concentration. With $\mathrm{pK}_{\mathrm{a}}=0.03$ [17] for the hydrolysis reaction

$$
\left[\mathrm{Mn}\left(\mathrm{H}_{2} \mathrm{O}\right)_{6}\right]^{3+} \leftrightarrow\left[\mathrm{Mn}\left(\mathrm{H}_{2} \mathrm{O}\right)_{5}(\mathrm{OH})\right]^{2+}+\mathrm{H}^{+}
$$

the electrolytes used here certainly span the range where this can occur. Hydrolysis of the hexaaquo $\mathrm{Mn}(\mathrm{III})$ species represents the initial step in precipitation of $\mathrm{MnOOH}$, with the $\mathrm{OH}^{-}$ligand able to undergo olation to form chains of octahedra extending from the electrode surface, as shown in Figure 3 [18]. This can be essentially regarded as a polymerization process with competition 
existing between chain growth (olation) and cross-linking both within and between chains. An important point indicated by Figure 3 is that the chains that are initially formed are still quite hydrated, which has the potential to increase electrode mass. These octahedral chains can then be oxidized further in the solid state to $\mathrm{Mn}(\mathrm{IV})\left(\mathrm{MnO}_{2}\right)$. At the more concentrated end of the $\mathrm{H}_{2} \mathrm{SO}_{4}$ concentration scale, hydrolysis according to Eqn (6) is less likely to occur meaning that the $\left[\mathrm{Mn}\left(\mathrm{H}_{2} \mathrm{O}\right)_{6}\right]^{3+}$ species formed are more stable, essentially introducing the possibility of $\mathrm{Mn}(\mathrm{III})$ disproportionation as a means to produce manganese dioxide. Its effectiveness is of course dependent on the stability of $\mathrm{Mn}(\mathrm{III})$, as well as the equilibrium constant for the disproportionation and the stability of Mn(IV) species. The disproportionation reaction

$$
2 \mathrm{Mn}^{3+}+2 \mathrm{H}_{2} \mathrm{O} \leftrightarrow \mathrm{Mn}^{2+}+\mathrm{MnO}_{2}+4 \mathrm{H}^{+}
$$

includes the $\mathrm{Mn}(\mathrm{IV})$ species as $\mathrm{MnO}_{2}$ since there is no evidence in the literature to suggest that the hexa-aquo $\mathrm{Mn}(\mathrm{IV})$ species $\left[\mathrm{Mn}\left(\mathrm{H}_{2} \mathrm{O}\right)_{6}\right]^{4+}$ has any degree of stability, it instead hydrolyzing to form manganese dioxide [17]. It has also been estimated from thermochemical data [19] that Eqn (7) has a heavily products-favoured equilibrium constant $\left(3 \times 10^{9}\right.$ at $\left.25^{\circ} \mathrm{C}\right)$, and therefore presuming that $\mathrm{Mn}(\mathrm{II})$ oxidation to $\mathrm{Mn}(\mathrm{III})$ is the first step in any mechanism; i.e.,

$$
\mathrm{Mn}^{2+} \rightarrow \mathrm{Mn}^{3+}+\mathrm{e}^{-}
$$

then the general mechanisms for manganese dioxide formation involve either a solid state route; i.e.,

$$
\begin{gathered}
\mathrm{Mn}^{3+}+2 \mathrm{H}_{2} \mathrm{O} \rightarrow \mathrm{MnOOH}+3 \mathrm{H}^{+} \\
\mathrm{MnOOH} \rightarrow \mathrm{MnO}_{2}+\mathrm{H}^{+}+\mathrm{e}^{-}
\end{gathered}
$$

or a disproportionation route involving Eqn (7). Both mechanisms are also expected to involve a significant number of dehydration steps; e.g., the formation of $\mathrm{MnOOH}$ in the solid state, and $\mathrm{MnO}_{2}$ formation from disproportionation of $\mathrm{Mn}(\mathrm{III})$.

The most obvious result from Figure 2(c) is the significantly larger mass of deposited manganese dioxide compared to the predicted value. The most logical explanation for this occurrence is that the manganese dioxide deposit is significantly hydrated, since the actual 
mechanism of deposition involves an number of dehydration steps [8-14]. The suggestion here is that dehydration of the deposit is relatively slow compared to the rate of deposition, leading to a greater than predicted electrode mass. This conclusion is supported by many of the $\gamma-\mathrm{MnO}_{2}$ deposition mechanisms proposed in the literature [8-14] which have suggested that dehydration of the deposited manganese oxide species plays a significant, perhaps rate limiting role. To quantify the extent of hydration we have calculated the $\mathrm{H}_{2} \mathrm{O}: \mathrm{MnO}_{2}$ ratio for each deposit (Table 1; "Predicted" data). In this case, this ratio was determined by presuming firstly that the excess electrode mass was due to water of hydration. Converting this mass to moles of water allows for easy comparison with the theoretical number of moles of manganese dioxide deposited on the electrode. The relatively large values of this ratio when $0,0.01$ and $0.1 \mathrm{M} \mathrm{H}_{2} \mathrm{SO}_{4}$ electrolytes were used does indicate significant hydration; however, from the number of coordinated water molecules present (1-5) during manganese oxide chain growth (Figure 3) certainly not all of the water content can be accounted for. Therefore, the remainder must be due to the presence of electrolyte filled pores within the manganese dioxide deposit. Clearly, as the $\mathrm{H}_{2} \mathrm{SO}_{4}$ electrolyte concentration decreases the greater the content of water included in pores within the deposit. Certainly many reports in the literature indicate that manganese oxides are quite porous [20], and so our conclusion in this case seems justified.

With the porous nature of the manganese dioxide deposit in mind, we can begin to speculate on its origin in terms of the various deposition mechanisms that we have suggested. The morphology of manganese dioxide, in particular $\gamma-\mathrm{MnO}_{2}$, has been examined previously through the use of TEM [5]. Essentially it can be described as a series of lathe-like crystallites $~ 10 \mathrm{~nm}$ wide and 50-200 nm long arranged into roughly spherical grains $200 \mathrm{~nm}$ in diameter. Porosity in the manganese dioxide exists between the individual crystallites, as well as between the grains. Commercial samples of $\gamma-\mathrm{MnO}_{2}$ can have BET surface areas in the range $10-80 \mathrm{~m}^{2} \cdot \mathrm{g}^{-1}$, indicating that they contain substantial porosity. It is reasonable to expect that material porosity correlates with crystallinity, since with smaller crystallites there are more boundary regions between crystallites 
and hence more opportunity for porosity to be present. Smaller crystallites are formed within a sample when the competition between crystal growth and nucleation is shifted more towards nucleation. Therefore, in the present case, decreasing the $\mathrm{H}_{2} \mathrm{SO}_{4}$ concentration may increase the rate of crystallite nucleation, thus forming a more porous deposit. This is also consistent with the solid state deposition mechanism proposed above in the sense that in electrolytes where the soluble $\mathrm{Mn}(\mathrm{III})$ intermediate is not stable there is the tendency to hydrolyze and precipitate $\mathrm{MnOOH}$. The instability of the soluble $\mathrm{Mn}$ (III) intermediate is such that nucleation of a new $\mathrm{MnOOH}$ crystallite is preferred over the continued growth of existing crystallites which apparently require greater Mn(III) stability.

Additional evidence to support the extent of $\mathrm{Mn}(\mathrm{III})$ stability in various $\mathrm{H}_{2} \mathrm{SO}_{4}$ electrolytes is apparent in the working electrode voltage during deposition, as shown in Figure 2(b) and in expanded form in Figure 4(a). This voltage profile is typical of a heterogeneous electrochemical reaction involving the formation of a soluble intermediate, which subsequently precipitates as a solid product. During the initial stages of electrolysis Mn(II) is oxidized to form a soluble Mn(III) intermediate, the concentration of which builds up at the electrode surface. The increasing electrode voltage is due to a greater proportion of the more oxidized Mn(III) at the electrode surface, as would be expected from a conventional solution-based chronopotentiometry experiment [21]. This saturates the electrode surface with $\mathrm{Mn}(\mathrm{III})$, the stability of which is dependent on the $\mathrm{H}_{2} \mathrm{SO}_{4}$ concentration. In low concentration electrolytes, where soluble Mn(III) stability is low, very little is formed before it hydrolyzes to produce the more stable $\mathrm{MnOOH}$ (which is subsequently oxidized to $\mathrm{MnO}_{2}$ ), or disproportionates to form $\mathrm{MnO}_{2}$ directly. Precipitation to form a solid product has the effect of removing soluble $\mathrm{Mn}(\mathrm{III})$ from the electrode interface, and when combined with the formation of a more stable, lower potential product $(\mathrm{MnOOH})$, the net effect is a decrease in the electrode voltage. Therefore, the time taken to reach the voltage peak $\left(\mathrm{V}_{\max }\right)$ can be used as an indicator of how long it takes to saturate the electrolyte in the vicinity of the electrode with Mn(III) (Figure 4(b)). The $\mathrm{V}_{\max }$ data in Table 1 clearly supports increased $\mathrm{Mn}(\mathrm{III})$ stability in higher $\mathrm{H}_{2} \mathrm{SO}_{4}$ 
electrolyte concentrations. Additionally, this hypothesis is consistent with the mass increase on the electrode after $\mathrm{V}_{\max }$; $c$. Figures 2(b) and (c). Eventually the electrode voltage levels off at a value representing heterogeneous oxidation of soluble $\mathrm{Mn}(\mathrm{II})$ to solid $\mathrm{MnO}_{2}$. The change in plateau voltage with $\mathrm{H} 2 \mathrm{SO} 4$ concentration indicates a $\mathrm{pH}$ dependence which can be quantified by $\mathrm{dE} / \mathrm{dpH}$. Here, $\mathrm{dE} / \mathrm{dpH}=-0.088 \mathrm{~V} /$ decade which is a mixed potential between Eqn (2) (-0.117 V/decade) and Eqn (10) (-0.059 V/decade).

Before going further let us revisit Table 1 and discuss the negative hydration level in the case of $1 \mathrm{M} \mathrm{H}_{2} \mathrm{SO}_{4}$ used as the electrolyte. While this is of course not physically possible, the negative value indicates a less than theoretical mass of deposit (Figure 2(c)). This situation can be interpreted by realizing that the stability of the $\mathrm{Mn}(\mathrm{III})$ intermediate increases as the $\mathrm{H}_{2} \mathrm{SO}_{4}$ concentration increases, meaning that with a longer lifetime in the electrolyte, the soluble $\mathrm{Mn}(\mathrm{III})$ species can actually diffuse away from the electrode interface and be lost to the bulk of the electrolyte. With a more stable $\mathrm{Mn}(\mathrm{III})$ intermediate we can also speculate that the significance of the disproportionation mechanism increases relative to $\mathrm{Mn}(\mathrm{III})$ hydrolysis.

As we have seen, the voltage profile during manganese dioxide deposition has proved useful in understanding the deposition mechanism. In addition, the voltage profile during the stripping portion of each experiment provides us with quantitative information on the amount of manganese dioxide actually deposited. The coulombic efficiency; i.e., the ratio of charge extracted during manganese dioxide reduction compared to the input charge for each of these experiments is also shown in Table 1. To calculate this data we have assumed that all of the manganese dioxide is reduced with $100 \%$ efficiency back to $\mathrm{Mn}(\mathrm{II})$ in solution, and that the voltage drop-off during the stripping portion in Figure 2(b) represents complete consumption of the manganese dioxide. The continued passage of cathodic current through the electrode, beyond that required to reduce the manganese dioxide, leads to another voltage plateau at much lower voltages, which we believe to be $\mathrm{H}_{2}$ evolution. The coulombic efficiency data in Table 1 indicates essentially the loss of soluble Mn(III) to the bulk of the electrolyte before hydrolysis or disproportionation can occur. The 
increasing coulombic efficiency as the $\mathrm{H}_{2} \mathrm{SO}_{4}$ concentration decreases again reflects the stability of Mn(III) under these conditions. Furthermore, now with a more accurate estimate of the amount of manganese dioxide on the electrode, the level of hydration can be recalculated, as shown in Table 1 (“Actual” data). Firstly, all values are positive and are hence more realistic. Secondly, each value is considerably larger than its corresponding predicted value indicating a much more hydrated deposit than originally expected. Finally, the trend in the extent of hydration for the deposits made in 0 , 0.01 and $0.1 \mathrm{M} \mathrm{H}_{2} \mathrm{SO}_{4}$ is consistent with our theoretical predictions, thus supporting our hypothesis that manganese dioxide porosity plays a significant role. The very high, inconsistent hydration level when $1.0 \mathrm{M} \mathrm{H}_{2} \mathrm{SO}_{4}$ was used is most likely due to only a very small amount of material being deposited and also a change in the deposition mechanism from Mn(III) hydrolysis to disproportionation.

\subsection{Manganese Concentration Effects}

To examine the effects of changing the Mn(II) concentration in the electrolyte we have employed a similar approach to that described above. A range of electrolytes with varying Mn(II) concentrations (0.01-1.0 $\mathrm{M} \mathrm{MnSO}_{4}$ ) and varying acid concentrations (0-1.0 $\mathrm{M} \mathrm{H}_{2} \mathrm{SO}_{4}$ ) were electrolyzed using the same current protocol as above. Table 2 contains a summary of the information extracted from the experimental data. As was discussed in the preceding section, it includes the maximum mass achieved, the actual level of hydration in the deposit, the coulombic efficiency and $\mathrm{V}_{\max }$.

It is quite interesting to compare the general trends in Table 2 for the total mass of manganese dioxide deposited, the actual level of hydration in the deposit and the coulombic efficiency when changes were made in the electrolyte Mn(II) concentration. An initial inspection of the data shows no discernable trend in the electrode mass as a function of Mn(II) concentration; however, it is clear that the level of hydration in the deposit increases as the Mn(II) concentration increases. For each experiment the relatively constant voltage profile towards the end of electrodeposition, as shown in 
Figure 2(b), is a clear indication the current density used was not high enough to cause Mn(II) depletion at the electrode surface. Therefore, since a constant amount of charge was passed during each electrodeposition experiment, and $\mathrm{Mn}(\mathrm{II})$ availability at the electrode surface was not a limitation, the amount of manganese dioxide deposited should then only be influenced by the actual mechanism of deposition, which we have so far seen to be very dependent on the $\mathrm{H}_{2} \mathrm{SO}_{4}$ concentration via its effect on $\mathrm{Mn}(\mathrm{III})$ intermediate stability. The increasing hydration level as the Mn(II) concentration increases (calculated via a decreasing coulombic efficiency), does indicate that the nature of the deposition process and the deposit itself are very dependent on the electrolyte Mn(II) concentration. In thinking about the way in which the mass of deposit can remain the same but the level of hydration increase, it must be that more Mn(II) rich electrolyte is occluded in the deposit, hence artificially boosting the mass of the deposit.

To understand this behaviour let us consider the local environment at the electrode surface while deposition is occurring. The first step in the overall process is the solution phase oxidation of $\mathrm{Mn}(\mathrm{II})$ to $\mathrm{Mn}(\mathrm{III})$. In higher concentration electrolytes, where the availability of $\mathrm{Mn}(\mathrm{II})$ is greater, we should expect the depletion layer to be much thinner due to the fact that with more Mn(II) ions available the mean distance they have to travel to sustain the applied current is less. Concurrent with this is the formation of a greater local concentration of $\mathrm{Mn}(\mathrm{III})$ at the electrode surface. In lower $\mathrm{H}_{2} \mathrm{SO}_{4}$ concentration electrolytes $(<1 \mathrm{M})$ the $\mathrm{Mn}(\mathrm{III})$ then undergoes hydrolysis and condensation to form $\mathrm{MnOOH}$ on the electrode surface. Changing the concentration of $\mathrm{Mn}(\mathrm{III})$ at the electrode interface would be expected to dramatically influence these steps in the mechanism. Firstly, with a higher concentration of $\mathrm{Mn}(\mathrm{III})$ the competition between $\mathrm{MnOOH}$ crystal nucleation and growth would have to be shifted more towards nucleation, since in a more concentrated environment more $\mathrm{Mn}(\mathrm{III})$ intermolecular collisions would occur, dramatically increasing the likelihood of nucleation. With more $\mathrm{MnOOH}$ nuclei being formed the porosity of the deposit must increase, and with that there is more opportunity for electrolyte to be occluded. Additional evidence to support this comes in the form of the time required after the onset of deposition to reach $\mathrm{V}_{\max }$ 
(Table 2), which essentially decreased as the $\mathrm{Mn}(\mathrm{II})$ concentration increased. In this instance the shorter time required for condensation and precipitation is a direct indicator of increased Mn(III) concentration at the electrode surface.

The preceding paragraph explains how more electrolyte can be occluded; however, it does not consider why less manganese dioxide is included into the deposit; i.e., lower coulombic efficiency in a constant mass deposit. The most logical explanation for this is that a greater fraction of Mn(III) formed at the electrode is lost to the bulk of the electrolyte before it can be precipitated onto the electrode. This in turn most likely occurs because of the higher inherent driving force to diffuse away from the electrode surface when a more concentrated Mn(III) layer is formed.

\subsection{Anodic Current Density Effects}

A typical example of the effects of anodic current density on the electrodeposition of manganese dioxide is shown in Figure 5. The data in this figure was collected using an electrolyte $0.1 \mathrm{M}$ in both $\mathrm{MnSO}_{4}$ and $\mathrm{H}_{2} \mathrm{SO}_{4}$, while electrodeposition was conducted at either 0.1 or $0.5 \mathrm{~mA}$ ( 0.075 or $0.375 \mathrm{~mA} \mathrm{~cm}{ }^{-2}$ ) for $30 \mathrm{~s}$ followed by a similar current density and duration stripping cycle.

Figure 5(a) shows the electrode mass change as a function of time, and as expected the use of a larger anodic current produced a heavier deposit, simply because more charge was passed in the deposition step. As has been observed previously, the actual deposit mass was greater than the theoretical amount indicating a significant amount of hydration within the deposit. Figure 5(b) shows a charge normalized massogram calculated from the data in Figure 5(a). For reference, charge normalization was conducted with respect to the lowest anodic current density experiment, which in the case of Figure 5(a) means that the $0.5 \mathrm{~mA}$ massogram data was divided by five to make it comparable to the $0.1 \mathrm{~mA}$ massogram. Inspection of the data in Figure 5(b) indicates that the use of a lower current density leads to an overall increase in the efficiency of deposition, although this needs to be tempered by the fact that we have not yet assessed the actual amount of 
manganese dioxide deposited. An interesting feature of the data in both Figures 5(a) and (b) is the residual mass remaining on the electrode when a $0.5 \mathrm{~mA}$ current was used. As we shall see shortly from a consideration of the voltage profiles, all of the manganese dioxide was electrochemically stripped from the electrode and so the origin of this residual mass is not immediately obvious. A possible explanation could be that after stripping the electrolyte in the immediate vicinity of the electrode is of a slightly higher density (different composition) compared to the bulk electrolyte when calibration of the EQCM was carried out. This localized compositional difference would of course be the result of the electrochemical reactions occurring on the electrode surface. Experimental evidence for this explanation was produced by continuing to monitor the electrode mass for a few more seconds after the stripping half-cycle was complete, in which case it decayed back to the baseline clearly indicating the dissipation of the more viscous layer back into the bulk of the electrolyte.

The corresponding deposition and stripping voltage profiles are shown in Figure 5(c). This data, combined with that contained in Figures 5(a) and (b), leads to the corresponding supplementary data in Table 3. To understand the overall effects of anodic current density let us begin by assessing its effect on the proposed electrodeposition mechanism. The use of a higher current density of course means that the electrochemical steps in the mechanism will be driven at a faster rate; i.e., oxidation of $\mathrm{Mn}(\mathrm{II})$ to $\mathrm{Mn}(\mathrm{III})$ (Eqn (8)) and $\mathrm{MnOOH}$ oxidation to $\mathrm{MnO}_{2}$ (Eqn (10)). On the electrolyte side of the interface this may mean that the Mn(II) depletion layer is thicker since more Mn(II) has to get to the electrode to sustain the current (particularly so since we are in a non-diffusion limited scenario). At the same time more Mn(III) would be produced in the vicinity of the electrode which would have a significant effect on its hydrolysis (Eqn (6)) and precipitation (Eqn (9)). Supporting evidence for this can be found in the time to $\mathrm{V}_{\max }$ data in Table 3, which shows clearly that at the higher anodic current density less time was required to reach $\mathrm{Mn}(\mathrm{III})$ saturation at the electrode surface and hence begin to precipitate $\mathrm{MnOOH}$.

Using the electrode voltage during the stripping half-cycle the amount of manganese dioxide 
actually deposited was identified, thus allowing determination of the coulombic efficiency (Table 3). Clearly it decreased considerably when a higher anodic current density was used. This is most probably due to the greater presence of $\mathrm{Mn}(\mathrm{III})$ in the vicinity of the electrode, and the subsequent loss of a larger fraction of $\mathrm{Mn}(\mathrm{III})$ to the bulk of the electrolyte before its hydrolysis and precipitation. From the coulombic efficiency the actual level of hydration within the deposit was determined, as shown in Table 3. The data also indicates that the use of higher current densities may lead to a more porous deposit. To explain this we have already indicated that a higher current density leads to a greater concentration of $\mathrm{Mn}(\mathrm{III})$ in the vicinity of the electrode after the first oxidation step. From a molecular point of view this means that there is an enhanced likelihood for $\mathrm{Mn}(\mathrm{III})$ ions to interact near the electrode surface and potentially form a crystal nucleation site. Therefore, with more Mn(III) present, more MnOOH nuclei should form, and with their subsequent condensation the bulk deposit so formed should have a greater number of smaller crystallites. Finally, with more interfacial area between crystallites, electrode porosity should increase.

\subsection{Commercial Comparison}

A comment needs to be made at this stage concerning the relationship between the conclusions we have reached so far and commercial electrolytic production of manganese dioxide. The electrolytes used during commercial production certainly fall within the bounds of the experiments we have conducted here. As such we should expect that the mechanistic framework we have developed should be at least broadly applicable. This is so because the effects of the other production variables (namely anodic current density and temperature) on the various steps in the mechanism are not well known.

The anodic current density used in the majority of experiments described here $\left(0.75 \mathrm{~A} \mathrm{~m}^{-2}\right)$ is of course very low compared to commercial anodic current densities (typically 50-80 A m² [7]). The intent in our work was to slow the entire mechanism down and hence at least try and observe individual step behaviour. Under commercial anodic current densities of course oxidation is 
occurring much faster. In the electrolyte the Mn(II) depletion layer would contribute significantly to concentration polarization if the electrolyte were quiescent; however, in commercial operations almost invariably the electrolyte is quite vigorously and chaotically stirred ensuring sufficient Mn(II) supply to the anode surface. This behaviour could also influence the electrode efficiency in terms of soluble intermediates being lost to the bulk of the electrolyte.

The temperature at which the electrodeposition occurs is also expected to have a significant effect on the mechanism. Our experiments in this work were conducted at $22 \pm 1^{\circ} \mathrm{C}$, whereas commercial EMD production occurs at temperatures greater than $95^{\circ} \mathrm{C}$ [7]. Attempts were made to study the electrodeposition at elevated temperatures; however, results from the EQCM were neither stable or reproducible due to the temperature sensitivity of the Sauerbrey equation [15] and our inability to maintain a steady elevated temperature. Nevertheless, we can speculate on the role that an increased temperature might play, in particular the effect that it has on intrinsic reaction rates. From an electrochemical standpoint we should expect an increase in exchange current density, and hence intrinsic charge transfer rate, as the temperature is raised. The net result of this would be a decrease in polarization as the temperature is increased. Perhaps the most important role that temperature plays, particularly in terms of material quality, is in influencing the rate of deposit dehydration and the competition between crystal growth and nucleation. Certainly an increase in temperature should be expected to increase the rate of dehydration. Evidence for this can be found by comparing the hydration levels determined in this work $\left(>10: 1 \mathrm{H}_{2} \mathrm{O}: \mathrm{MnO}_{2}\right)$ with the structural water content of a commercial EMD ( 4\% structural water which equates to 1:5 $\mathrm{H}_{2} \mathrm{O}: \mathrm{MnO}_{2}$ ). The much lower hydration level can primarily be accounted for by the elevated temperature; however, there are also the effects of temperature on crystallite growth and nucleation that need to be considered. From the excessive hydration levels determined in this work, we would be correct in assuming that beyond a hydration level of about 3:1 $\mathrm{H}_{2} \mathrm{O}: \mathrm{MnO}_{2}$ (which is a very generous estimate) the remaining water is occluded in pores, indicating that the manganese dioxide deposit is indeed very porous (estimated pore volume of $\sim 0.8 \mathrm{~cm}^{3} \mathrm{~g}^{-1}$ based on a hydration level of 7:1 $\mathrm{H}_{2} \mathrm{O}: \mathrm{MnO}_{2}$ ). 
The pore volume of commercial EMD can vary substantially, but a good estimate is $\sim 0.035 \mathrm{~cm}^{3} \mathrm{~g}^{-1}$ [20] which is of course much less. The origin of this porosity lies in the assembly and size of the EMD crystallite, with smaller crystallites giving rise to a greater porosity. Therefore, it seems logical that an increase in deposition temperature favours crystallite growth compared to nucleation.

\section{SUMMARY AND CONCLUSIONS}

The electrochemical quartz crystal microbalance (EQCM) has been used to examine the effects of electrolyte composition and anodic current density on the electrodeposition of manganese dioxide. A cross section of electrolyte compositions encompassing 0-1 $\mathrm{M} \mathrm{H}_{2} \mathrm{SO}_{4}$ and 0.01-1 $\mathrm{M}$ $\mathrm{MnSO}_{4}$, and current densities $\left(0.075-0.375 \mathrm{~mA} \mathrm{~cm}^{-2}\right)$ were examined in terms of their massogram and voltage profile during both deposition and stripping at an anodic current density of $0.075 \mathrm{~mA}$ $\mathrm{cm}^{-2}$ and temperature of $22^{\circ} \mathrm{C}$. Interpretation of the results has led to the following conclusions:

(i) The $\mathrm{H}_{2} \mathrm{SO}_{4}$ concentration plays a significant role in the overall deposition mechanism, particularly through its effects on the stability of the Mn(III) intermediate. In this particular case, when higher $\mathrm{H}_{2} \mathrm{SO}_{4}$ concentration electrolytes were used, an increasing amount of $\mathrm{Mn}(\mathrm{III})$ intermediate was lost to the bulk of the electrolyte before its hydrolysis to form a solid product on the electrode.

(ii) The level of hydration (or porosity) within the manganese dioxide deposits is affected by all synthesis variables considered. Increasing the $\mathrm{H}_{2} \mathrm{SO}_{4}$ and $\mathrm{MnSO}_{4}$ concentrations, as well as the anodic current density increases the relative hydration level within the deposit. The effects of each of these variables were considered on a molecular level in terms of the impact they have on increasing crystal nucleation rather than growth.

(iii) A comparison was made between the experimental conditions used here and commercial electrodeposition. The range of electrolyte compositions examined was comparable; however, much 
lower anodic current densities and temperatures were used. Predictions were made as to which components of the deposition mechanism would be affected by these variables.

\section{ACKNOWLEDGEMENTS}

The authors would like to acknowledge the technical and financial contributions made to this work by Dr. Rodney Williams and Andrew Manditch, both of Delta EMD, Australia Pty Limited. The Australian Research Council is also acknowledged for their financial contributions through the Linkage Project scheme (LP0346943).

\section{REFERENCES}

[1] P. M. De Wolff, Acta Cryst., 12 (1959) 341.

[2] P. Ruetschi, J. Electrochem. Soc., 131 (1984) 2737.

[3] P. Ruetschi, J. Electrochem. Soc., 135 (1988) 2657.

[4] Y. Chabre and J. Pannetier, Prog. Solid State Chem., 23 (1995) 1.

[5] A. H. Heuer, A. Q. He, P. J. Hughes and F. H. Feddrix, ITE Lett. Batt., New Tech. Med., 1 (2000) 926.

[6] C. H. Kim, Z. Akase, L. Zhang, A. H. Heuer, A. E. Newman and P. J. Hughes, J. Solid State Chem., 179 (2006) 753.

[7] C. B. Ward, A. I. Walker and A. R. Taylor, Prog. Batt. Batt. Mater., 11 (1992) 40.

[8] M. Fleischmann, H. R. Thirsk and I. M. Tordesillas, Trans. Faraday Soc., 58 (1962) 1865.

[9] A. Cartwright and R. L. Paul, Proceedings of the $\mathrm{MnO}_{2}$ Symposium, Vol. 2, Eds. B. Schumm, H. M. Joseph and A. Kozawa (1980) 290.

[10] R. L. Paul and A. Cartwright, J. Electroanal. Chem., 201 (1986) 113.

[11] R. L. Paul and A. Cartwright, J. Electroanal. Chem., 201 (1986) 123. 
[12] E. Preisler, Proceedings of the $2^{\text {nd }}$ Battery Materials Symposium, Eds. K. V. Kordesch and A. Kozawa, Graz, 1985.

[13] W. H. Kao and V. J. Weibull, J. Appl. Electrochem., 22 (1992) 21.

[14] C. J. Clarke, G. J. Browning and S. W. Donne, Electrochim. Acta, 51 (2006) 5773.

[15] G. Sauerbrey, Z. Phys., 155 (1959) 206.

[16] G. Aylward and T. Findlay, SI Chemical Data, $4^{\text {th }}$ Ed., John Wiley and Sons, 1998.

[17] F. A. Cotton, G. Wilkinson, C. A. Murillo and M. Bochmann, Advanced Inorganic Chemistry, $6^{\text {th }}$ ed., John Wiley and Sons, 1999.

[18] C. J. Brinker and G. W. Scherer, Sol-Gel Science, Academic Press, 1989.

[19] J. Y. Welsh, Electrochem. Tech., 5 (1967) 504.

[20] D. A. J. Swinkels, N. Bristow and R. P. Williams, Prog. Batt. Batt. Mater., 13 (1994) 12.

[21] A. J. Bard and L. R. Faulkner, Electrochemical Methods: Fundamentals and Applications, John Wiley and Sons, 1982. 

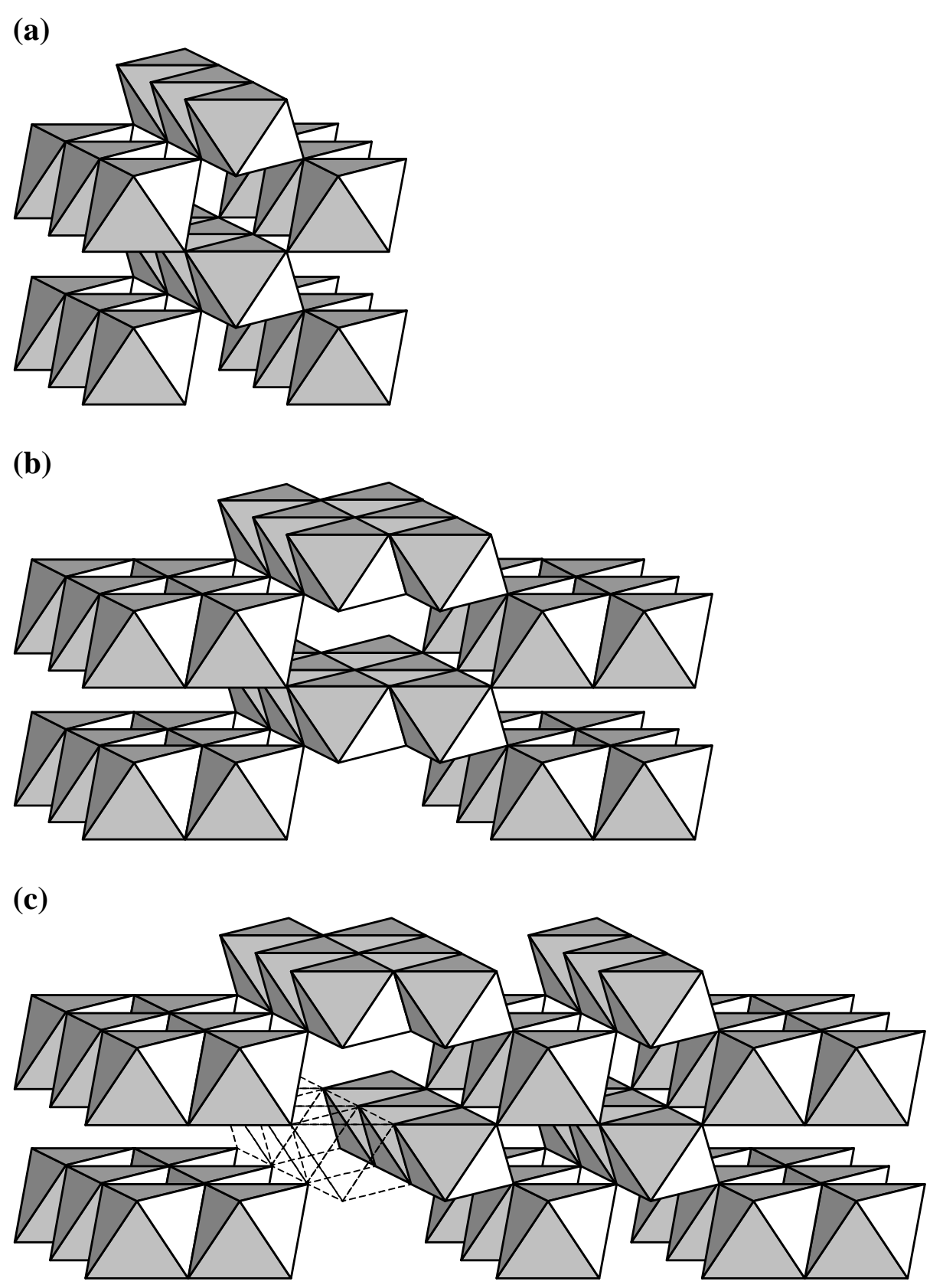

Figure 1. Structural components of $\gamma-\mathrm{MnO}_{2}$. (a) Pyrolusite $\left(\beta-\mathrm{MnO}_{2}\right)$; (b) Ramsdellite; and (c) $\gamma$ $\mathrm{MnO}_{2}$. 
(a)

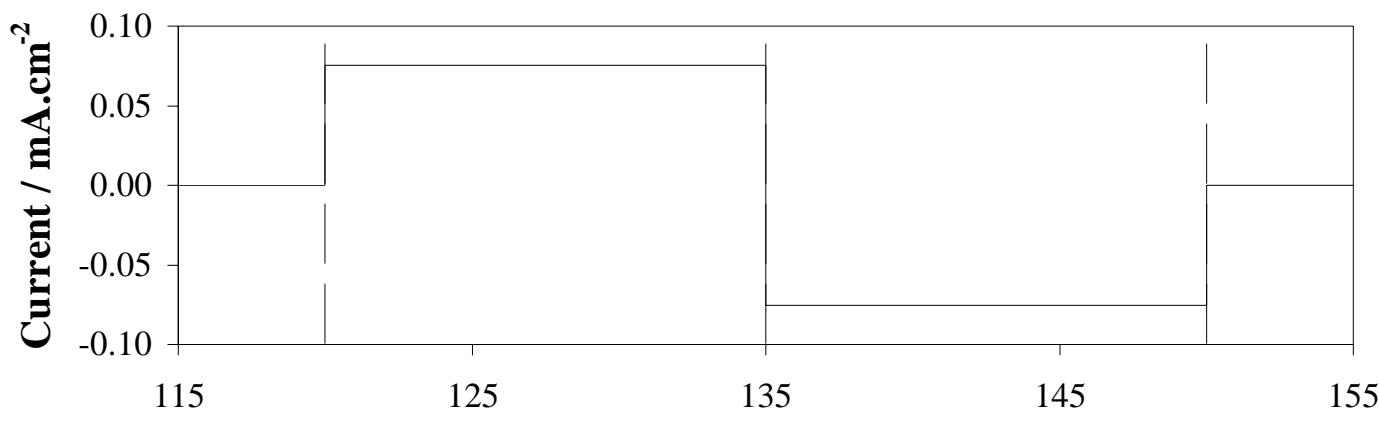

Time / s

(b)

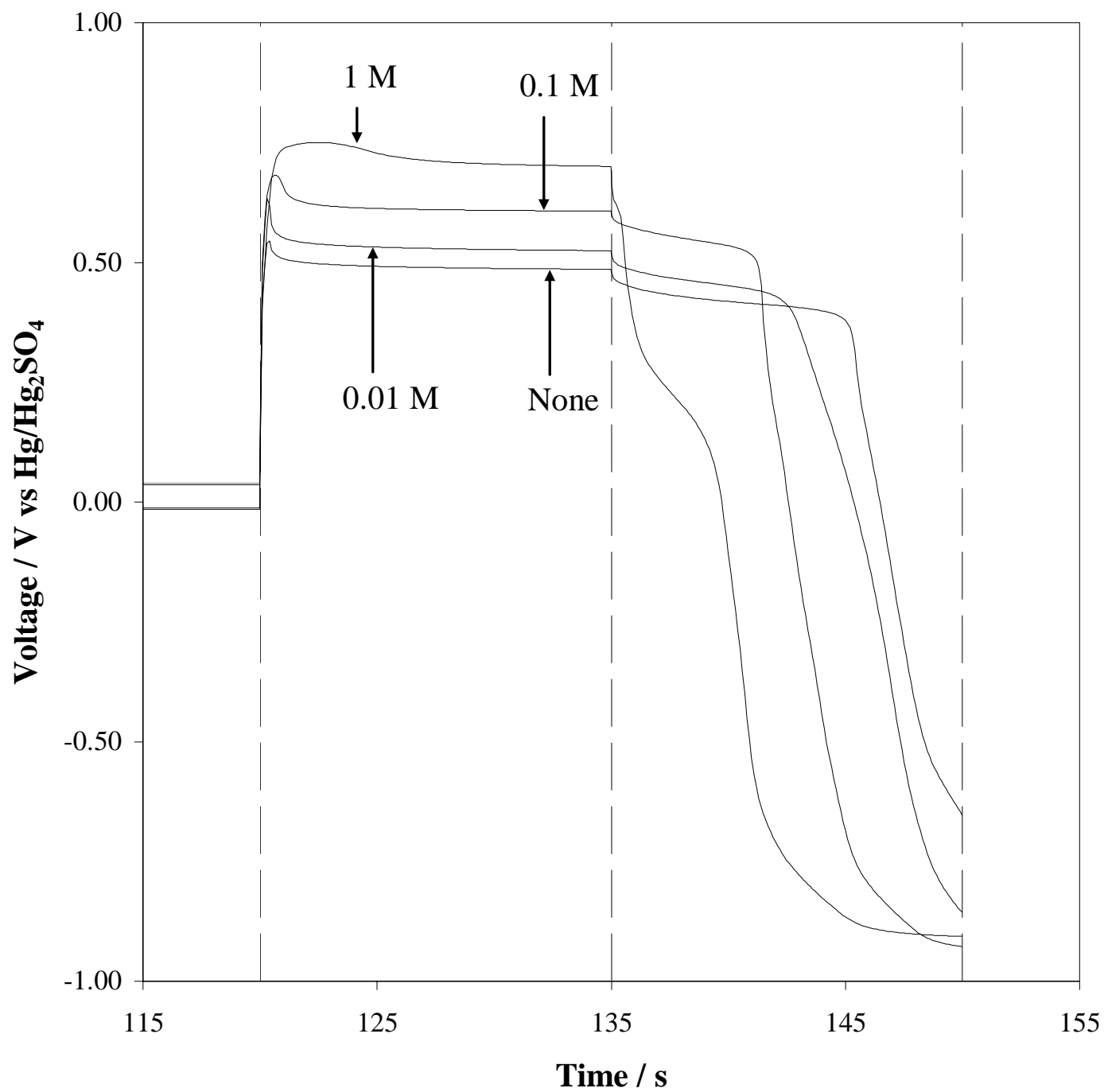


(c)

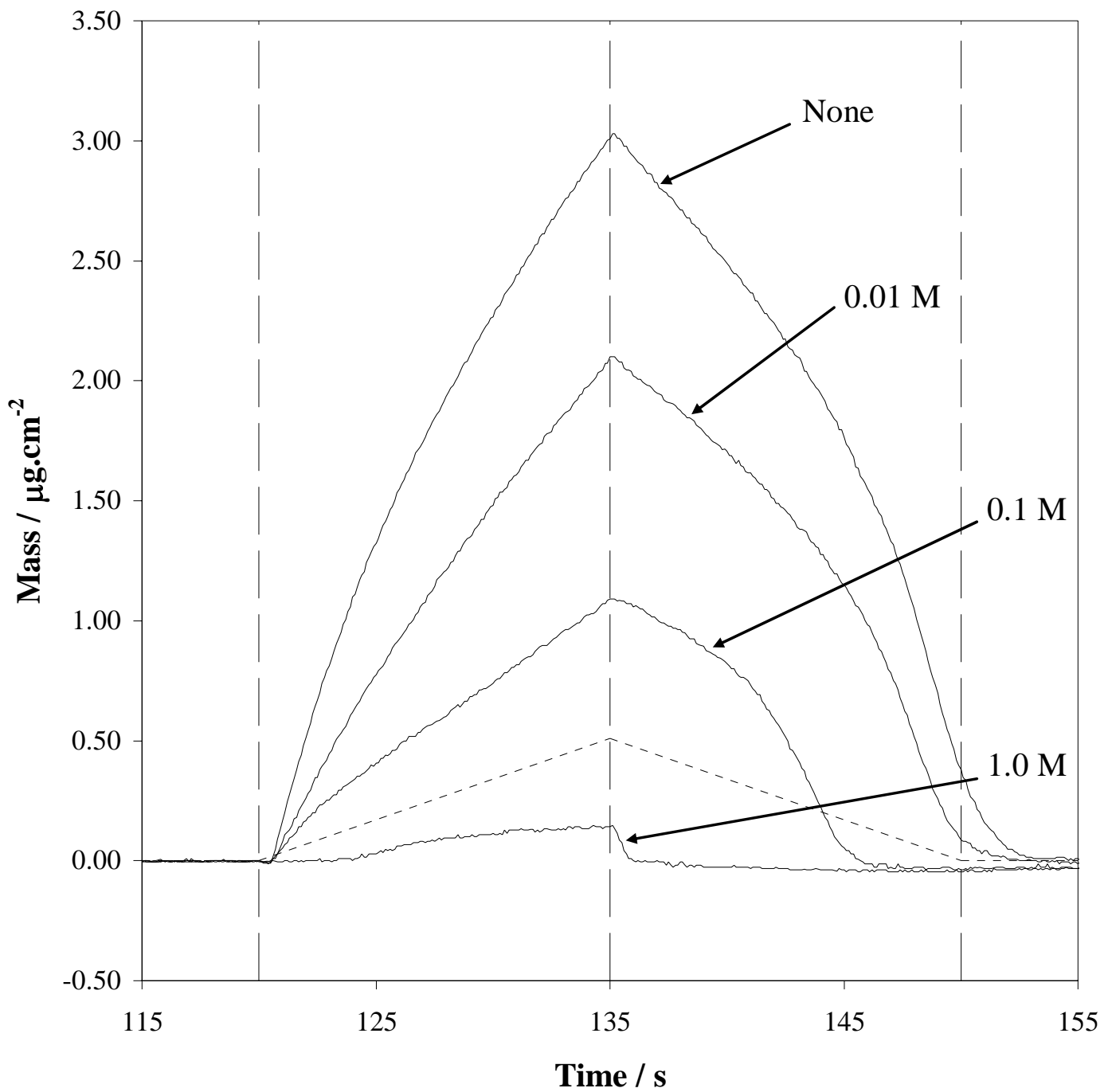

Figure 2. Sample EQCM results indicating the effects of $\mathrm{H}_{2} \mathrm{SO}_{4}$ concentration $\left(1 \mathrm{M} \mathrm{MnSO}_{4}\right)$ : (a) electrolysis profile; (b) deposition and stripping voltages; and (c) mass change data. The dotted line in (c) represents the theoretical mass predicted based on the stoichiometry of Eqn (4) and the molecular weight of $\mathrm{MnO}_{2}$. 

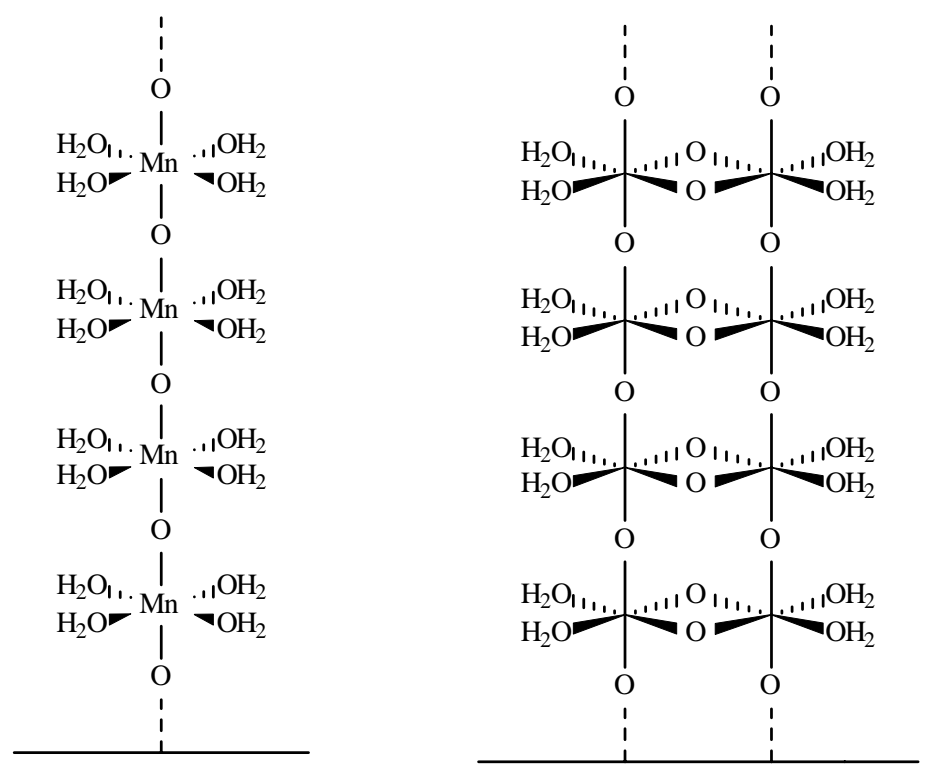

Figure 3. Condensation of $\left[\mathrm{Mn}\left(\mathrm{H}_{2} \mathrm{O}\right)_{6}\right]^{3+}$ species to form (a) single chains and (b) cross-linked chains. 
(a)

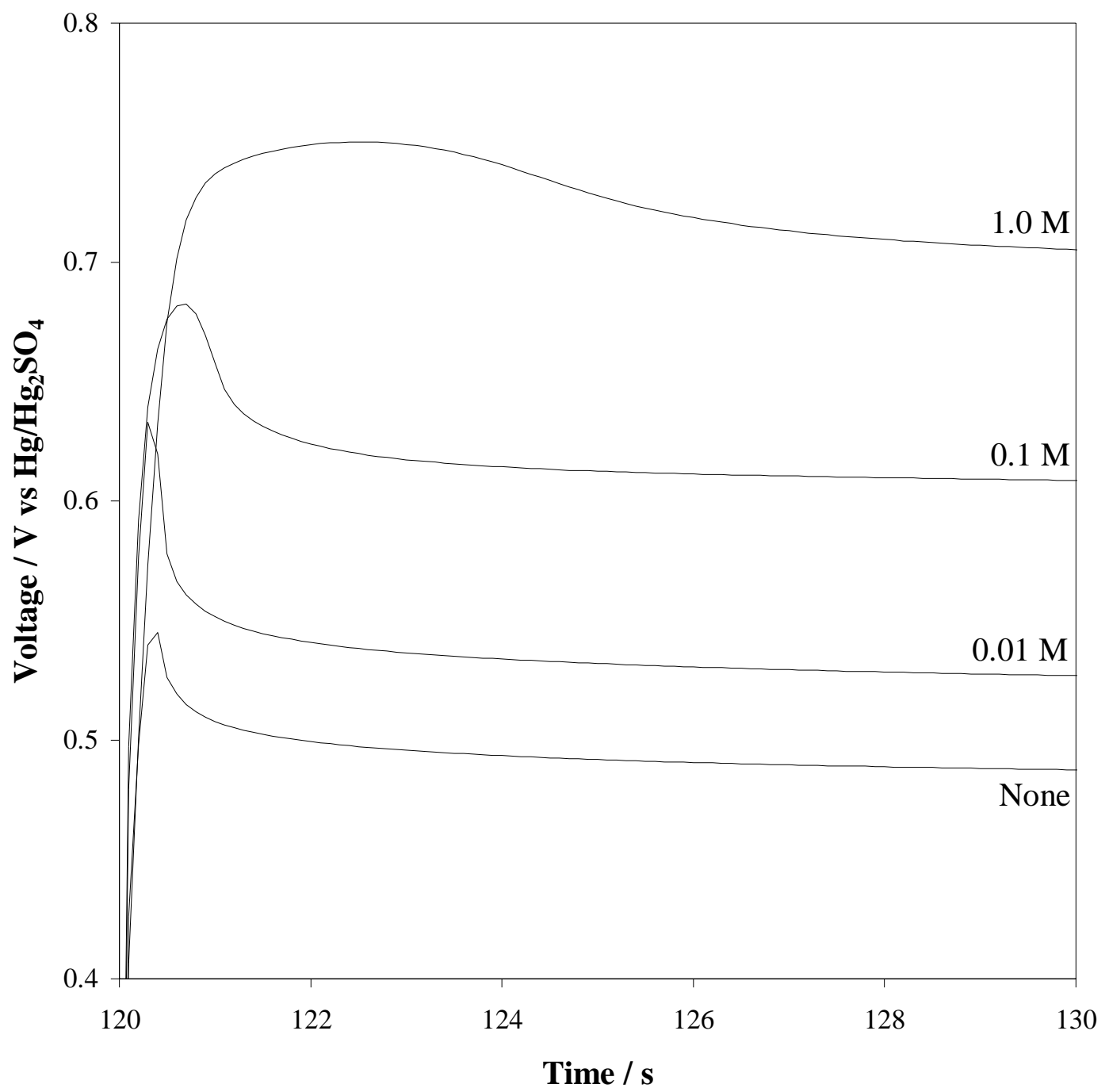


(b)

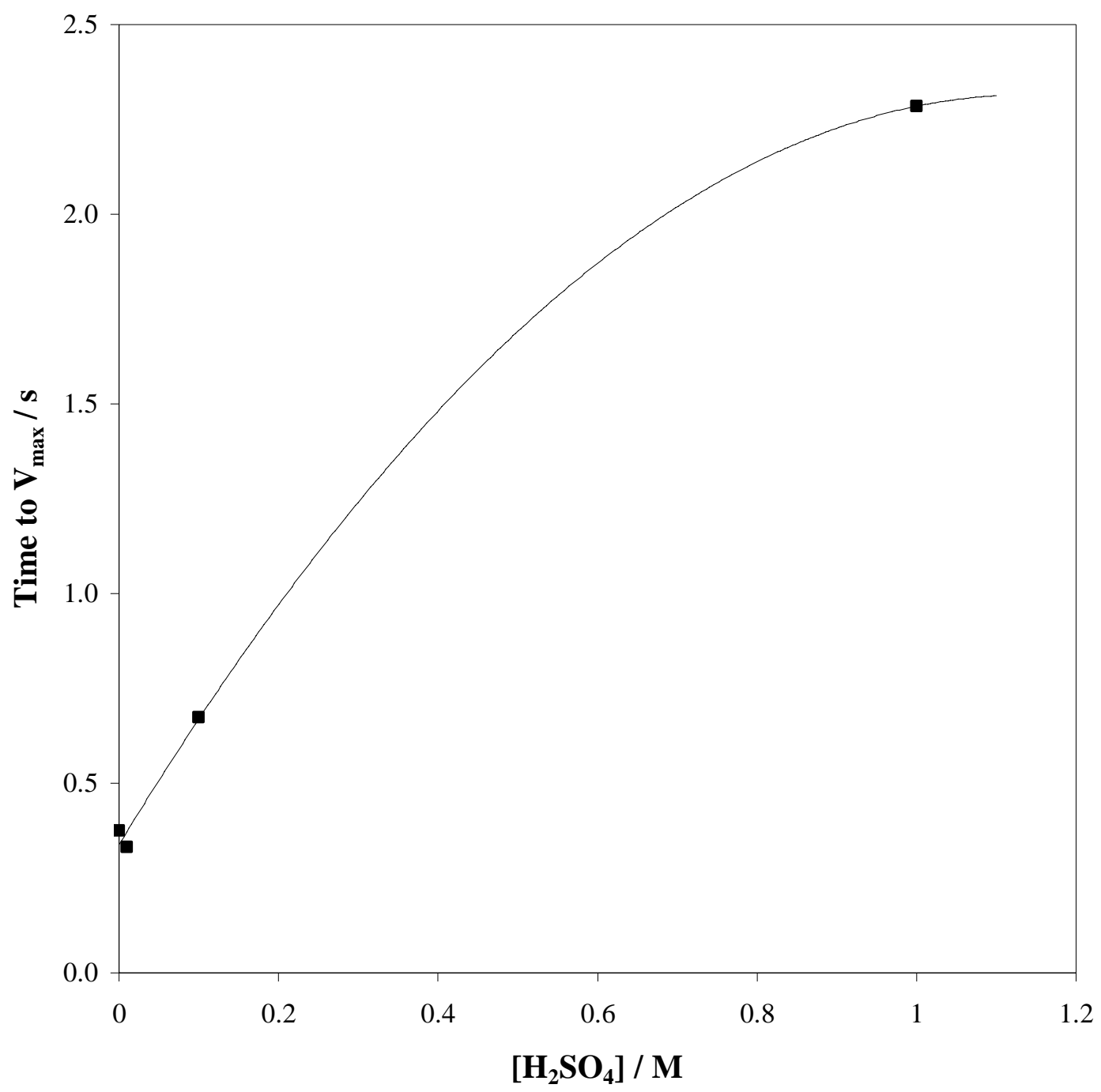

Figure 4. (a) Working electrode voltage profile during electrodeposition of manganese dioxide in different concentration $\mathrm{H}_{2} \mathrm{SO}_{4}$ electrolytes $\left(1 \mathrm{M} \mathrm{MnSO}_{4} ; 0.075 \mathrm{~mA} . \mathrm{cm}^{-2}\right)$; $c f$. Figure 2(b). (b) Time to voltage maximum $\left(\mathrm{V}_{\max }\right)$ for the data in (a). 
(a)

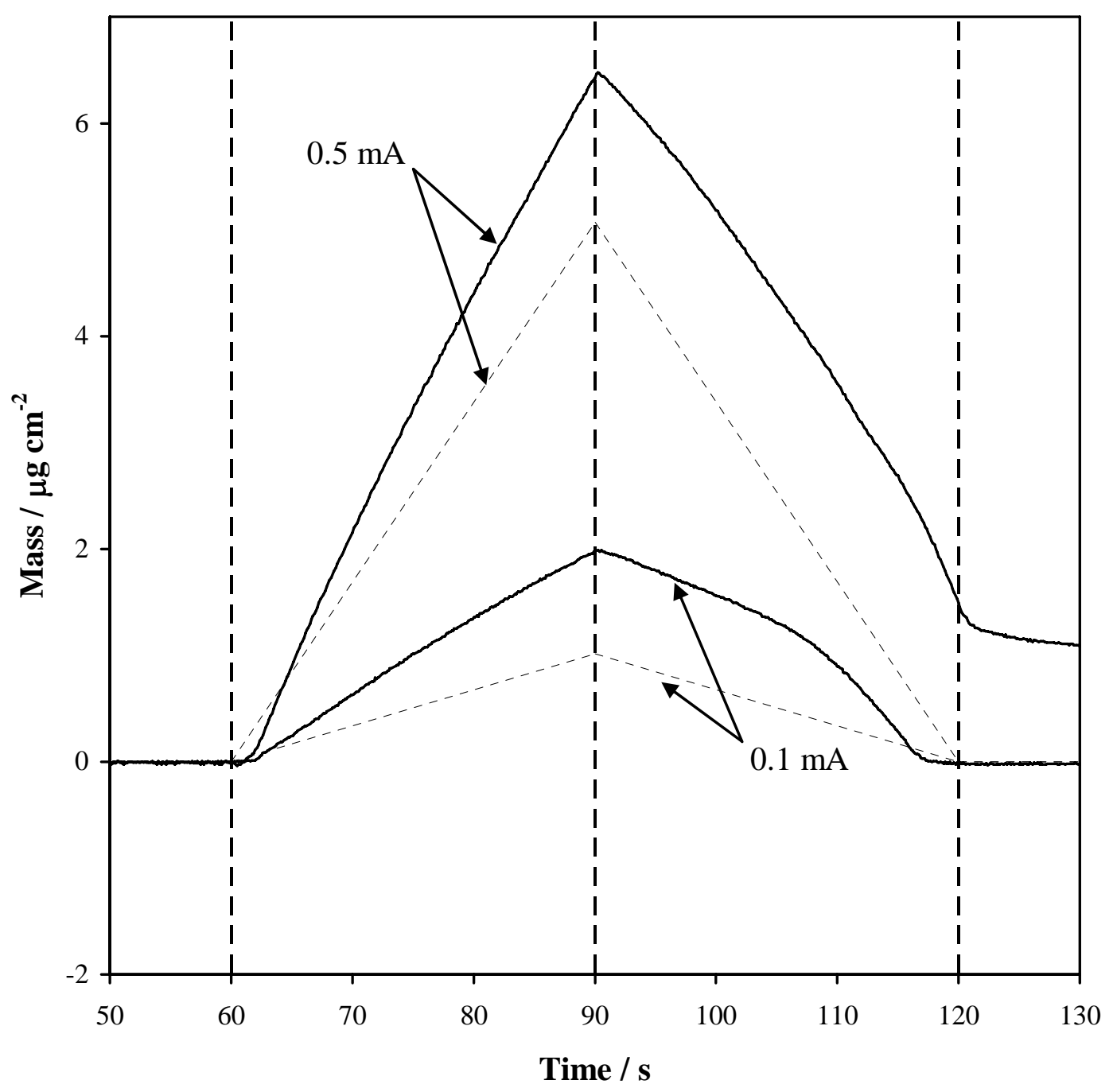


(b)

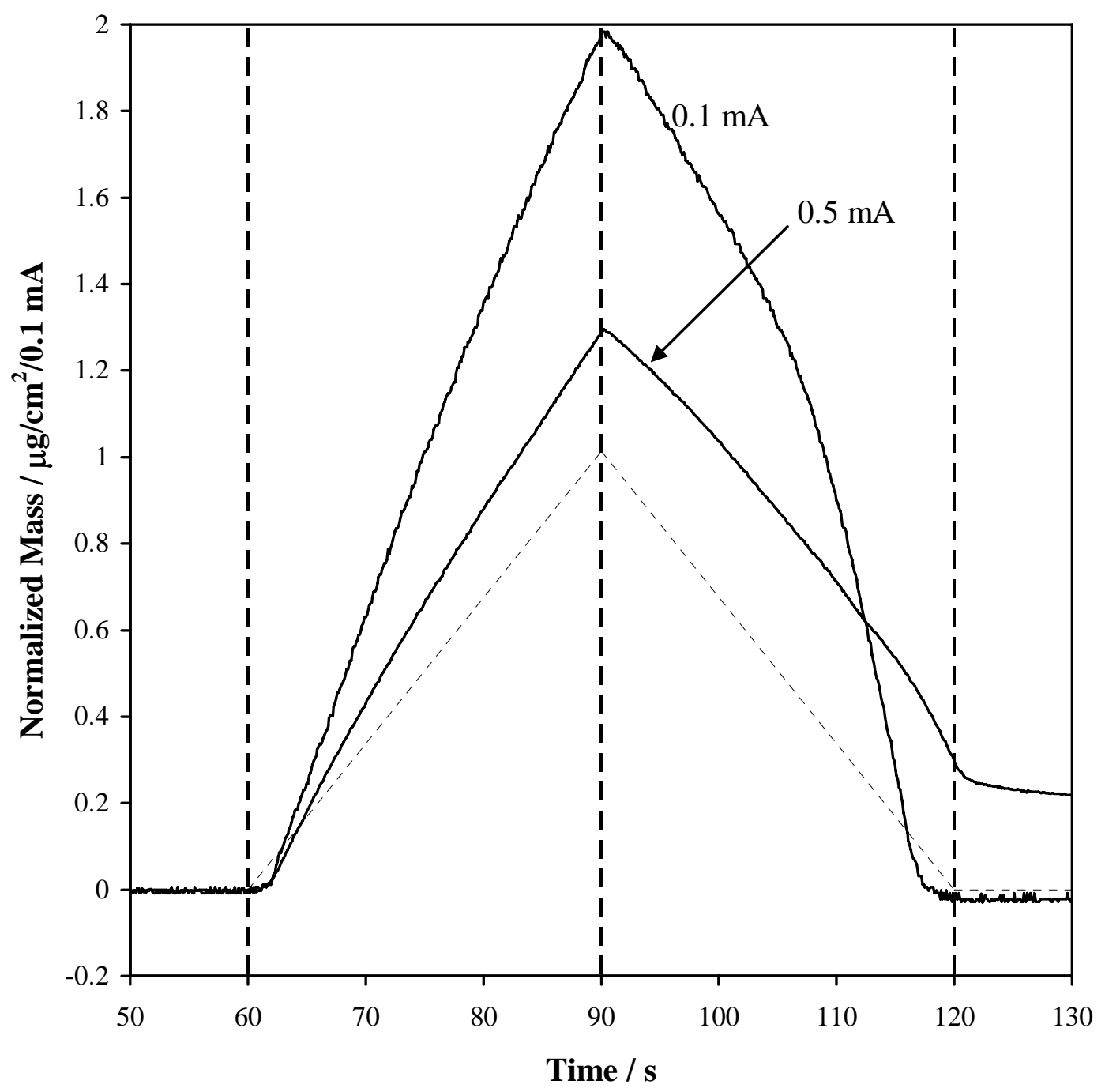


(c)

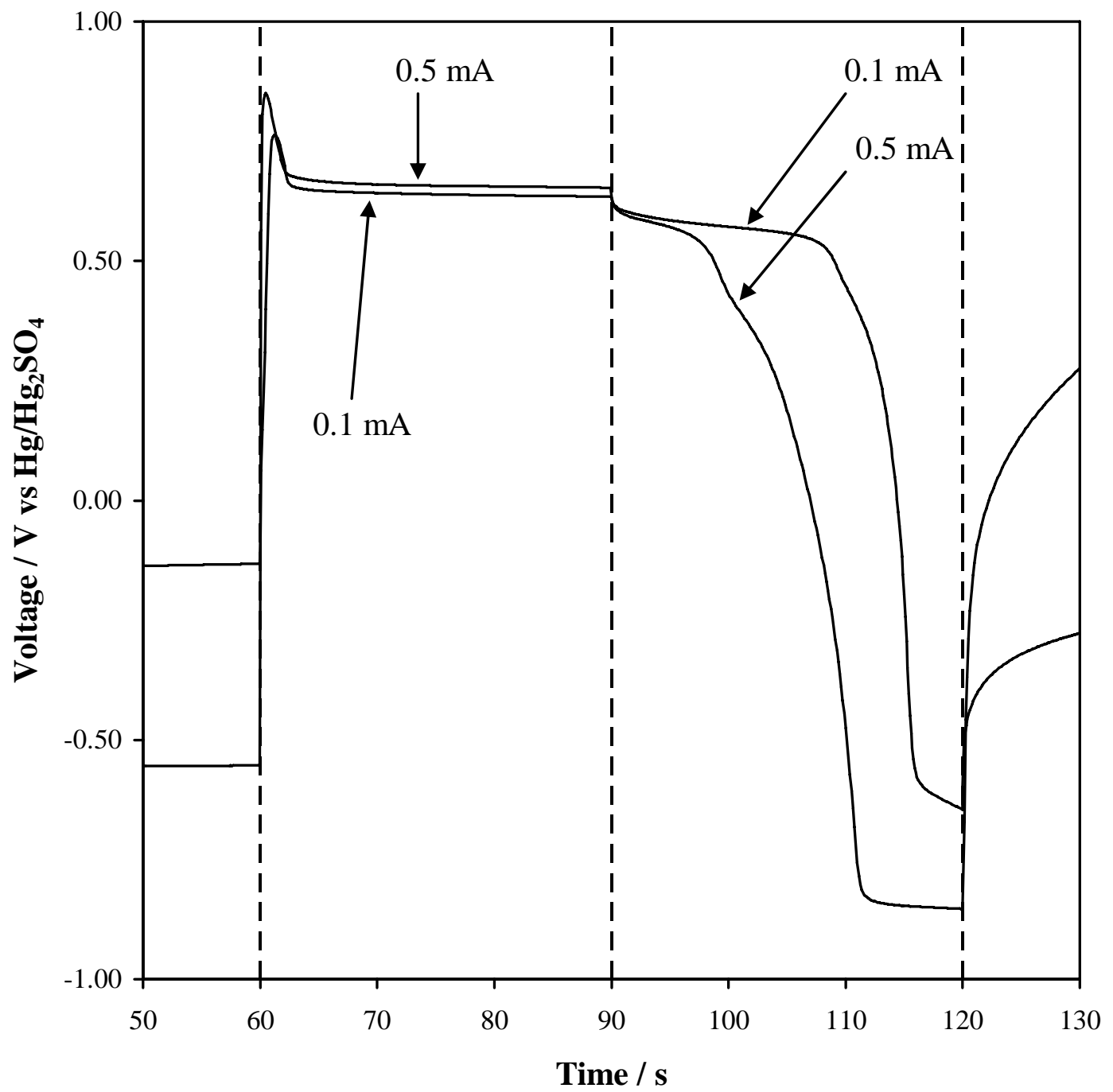

Figure 5. Example showing the effects of current density on manganese dioxide electrodeposition. $0.1 \mathrm{M} \mathrm{MnSO}_{4}+0.1 \mathrm{M} \mathrm{H}_{2} \mathrm{SO}_{4}$ with electrolysis at 0.1 or $0.5 \mathrm{~mA}\left(0.075\right.$ or $\left.0.375 \mathrm{~mA} / \mathrm{cm}^{2}\right)$ for $60 \mathrm{~s}$. (a) Massogram; (b) normalized massogram; and (c) voltage profile during deposition and stripping. In (a) and (b) the dotted line represents the expected mass predicted based on the stoichiometry of Eqn (4) and the molecular weight of $\mathrm{MnO}_{2}$. 
Table 1. Data collected from the experiments examining the effects of different $\mathrm{H}_{2} \mathrm{SO}_{4}$ concentrations.

\begin{tabular}{cccccc} 
[H $\left._{2} \mathbf{S O}_{\mathbf{4}}\right]$ & $\begin{array}{c}\text { Actual } \\
\text { Mass }\end{array}$ & $\begin{array}{c}\text { Predicted } \\
\text { Mass }\end{array}$ & \multicolumn{2}{c}{$\begin{array}{c}\text { Hydration } \\
\left.\mathbf{( H}_{\mathbf{2}} \mathbf{O}: \mathbf{M n O}_{\mathbf{2}}\right)\end{array}$} & $\begin{array}{c}\text { Coulombic } \\
\text { Efficiency }\end{array}$ \\
$\mathbf{( M )}$ & $\left(\mu \mathbf{g} \cdot \mathbf{c m}^{-2}\right)$ & $\left(\boldsymbol{\mu g} \cdot \mathbf{c m}^{-2}\right)$ & Predicted & Actual & $\mathbf{( \% )}$ \\
0 & 3.029 & & 23.9 & 26.1 & 70 \\
0.01 & 2.100 & & 15.1 & 21.7 & 61 \\
0.1 & 1.090 & 0.509 & 5.5 & 13.2 & 43 \\
1.0 & 0.147 & & -3.4 & 21.5 & 4
\end{tabular}

Table 2. Experimental data examining the effects of electrolyte composition ([ $\left.\mathrm{H}_{2} \mathrm{SO}_{4}\right]$ and [Mn(II)]. $\left(^{*}\right)$ indicates an experiment where a voltage maxima during deposition was not observed, hence the inconsistent data.

\begin{tabular}{|c|c|c|c|c|c|}
\hline $\begin{array}{l}{\left[\mathrm{H}_{2} \mathrm{SO}_{4}\right]} \\
(\mathrm{M})\end{array}$ & $\begin{array}{l}{[\mathrm{Mn}(\mathrm{II})]} \\
(\mathrm{M})\end{array}$ & $\begin{array}{c}\text { Mass } \\
\left(\mu \mathrm{g} . \mathrm{cm}^{-2}\right)\end{array}$ & $\begin{array}{c}\text { Hydration } \\
\left(\mathrm{H}_{2} \mathrm{O}: \mathrm{MnO}_{2}\right)\end{array}$ & $\begin{array}{c}\text { Coulombic } \\
\text { Efficiency } \\
(\%)\end{array}$ & $\begin{array}{l}V_{\max } \\
(s)\end{array}$ \\
\hline \multirow[t]{3}{*}{0} & 0.01 & 3.502 & 34.6 & 63 & 0.25 \\
\hline & 0.1 & 2.987 & 25.9 & 69 & 0.25 \\
\hline & 1.0 & 3.029 & 26.1 & 70 & 0.37 \\
\hline \multirow[t]{3}{*}{0.01} & 0.01 & 1.753 & 11.9 & 75 & 1.34 \\
\hline & 0.1 & 1.892 & 12.0 & 80 & 0.49 \\
\hline & 1.0 & 2.100 & 21.7 & 57 & 0.33 \\
\hline \multirow[t]{3}{*}{0.1} & 0.01 & 1.320 & 7.0 & 79 & 1.37 \\
\hline & 0.1 & 1.340 & 8.8 & 70 & 1.18 \\
\hline & 1.0 & 1.090 & 13.2 & 43 & 0.67 \\
\hline \multirow[t]{3}{*}{1.0} & 0.01 & 0.002 & -4.1 & 2 & $15.00 *$ \\
\hline & 0.1 & 0.248 & 15.6 & 9 & 4.55 \\
\hline & 1.0 & 0.147 & 21.5 & 4 & 2.28 \\
\hline
\end{tabular}

Table 3. Experimental data examining the effects of anodic current density $\left(0.1 \mathrm{M} \mathrm{MnSO}_{4}+0.1 \mathrm{M}\right.$ $\left.\mathrm{H}_{2} \mathrm{SO}_{4}\right)$.

\begin{tabular}{|c|c|c|c|c|c|}
\hline \multirow{2}{*}{$\begin{array}{l}\text { Current Density } \\
\qquad\left(\mathrm{mA} \mathrm{cm}^{-2}\right)\end{array}$} & \multicolumn{2}{|c|}{$\begin{array}{c}\text { Mass } \\
\left(\mu \mathrm{g} . \mathrm{cm}^{-2}\right)\end{array}$} & \multirow{2}{*}{$\begin{array}{l}\text { Hydration } \\
\left(\mathrm{H}_{2} \mathrm{O}: \mathrm{MnO}_{2}\right)\end{array}$} & \multirow{2}{*}{$\begin{array}{c}\text { Coulombic } \\
\text { Efficiency } \\
(\%)\end{array}$} & \multirow{2}{*}{$\begin{array}{l}V_{\max } \\
(s)\end{array}$} \\
\hline & Raw & Normalized & & & \\
\hline 0.075 & 1.984 & 1.984 & 7.5 & 64 & 1.18 \\
\hline 0.375 & 6.479 & 1.296 & 15.7 & 31 & 0.48 \\
\hline
\end{tabular}

